\title{
Temporal Trends Of Pharmacologic Therapies For Patients With Chronic Obstructive Pulmonary Disease In Alberta, Canada
}

This article was published in the following Dove Press journal: International Journal of Chronic Obstructive Pulmonary Disease

\author{
Dat T Tran (iD) ${ }^{1,2}$ \\ Ilke Akpinar (iD) \\ Irvin Mayers iD $^{3}$ \\ Tatiana Makhinova (iD) ${ }^{2}$ \\ Philip Jacobs ${ }^{3}$ \\ 'Institute of Health Economics, \\ Edmonton, Alberta, Canada; ${ }^{2}$ Faculty of \\ Pharmacy and Pharmaceutical Sciences, \\ University of Alberta, Edmonton, \\ Alberta, Canada; ${ }^{3}$ Faculty of Medicine, \\ University of Alberta, Edmonton, \\ Alberta, Canada
}

Objectives: To describe the trends in pharmacologic treatment for patients newly diagnosed with chronic obstructive pulmonary disease (COPD) in Alberta, Canada.

Methods: We linked Alberta health databases to identify patients aged $\geq 35$ years with incident COPD between April 2010 and March 2017. Incident cases were defined as those who did not have a hospitalization or outpatient visit with COPD in the previous 2 years. Patients were categorized into two groups: 1) incident cases at a hospital and 2) incident cases at an outpatient clinic, and both were followed until death or being censored by 31 March 2018. Utilization of COPD medication for 30 days following incident event and adherence in maintenance therapy over time were reported.

Results: The study included 33,169 patients with incident COPD (hospital: 9,089; outpatient: 24,080). In 18,666 (56.3\%) patients starting medication within 30 days of the incident event (2010: 52.7\%; 2016: 56.6\%; $\mathrm{p}=0.002$ ), SABA $(60.5 \%)$ and LABA/ICS $(41.6 \%)$ were most commonly used. ICS (without LABA) was used in $14.2 \%$ and was used as monotherapy in $4.5 \%$ of patients. The proportion of patients who initiated any ICS was similar (hospital: $56.7 \%$; outpatient: $55.7 \%$; $=0.194$ ) and decreased in both settings over time $(\mathrm{p}<0.001)$. Drug adherence during the first year after the incident event was $54.3 \%$, higher among hospital patients $(66.5 \%$ vs $48.9 \%$; $<<0.001)$, and improved over time $(2010$ : 53.4\%; 2016: 57.4\%; $<<0.001)$.

Conclusion: The initiation of and adherence to pharmacologic therapy for patients with COPD is low but improves over time. While SABA and LABA/ICS are most commonly used, ICS utilization decreases over time.

Keywords: COPD, drug utilization, pharmacologic therapy, Canada

\section{Introduction}

Chronic obstructive pulmonary disease (COPD) is common, preventable, and treatable. The aim of treatment is to relieve symptoms, prevent, and treat exacerbations, mitigate disease progression, enhance quality of life, and reduce mortality. ${ }^{1}$ Despite the best available therapy, COPD was one of the leading causes of life years lost in 2016 globally, and is a leading cause of mortality and morbidity in Canada. ${ }^{2,3}$ COPD is common among the elderly. The prevalence of COPD in Canada could be as high as $12 \%$, and it is expected to increase further as the Canadian population ages. ${ }^{4,5}$

In combination with non-pharmacologic approaches (e.g., smoking cessation, physical activity, and pulmonary rehabilitation), pharmacologic therapy is an important component of an effective management plan for patients with COPD. It improves health
Correspondence: Dat T Tran Institute of Health Economics, \#I200 10405 Jasper Avenue, Edmonton, Alberta T5J 3N4, Canada

Tel + I 780448488 |

Fax +17804480018

Email dttran@ualberta.ca 
status and reduces symptoms (e.g., dyspnea, cough, and sputum), frequency and severity of exacerbations, and hospital admissions. $^{6}$

There are a number of studies evaluating initiation of drug therapy after the first COPD diagnosis. In a population-based study between 1997 and 2012 in Manitoba, Canada, Falk et al reported a significant number of patients with COPD not taking any medication during follow-up, overuse of inhaled corticosteroids (ICS)-containing regimens, and an increasing trend in the use of long-acting bronchodilator (LABD)-containing medications. ${ }^{7}$ Similarly, Ford et al reported a strong increase in the use of short-acting $\beta$-2 agonists (SABA), LABD, and ICS between 1999 and 2010 in the United States. ${ }^{8}$ In terms of guideline adherence, only $34 \%$ of patients in a study in Quebec and Ontario, Canada, were reported to have treatments that follow guideline recommendations. This percentage is on par with results of a study in Denmark where the use of and adherence to COPD medication were low. ${ }^{9,10}$

Alberta, Canada, has an integrated, publicly funded, and universally covered health care system with a single, province-wide institutional service provider (Alberta Health Services) serving a population of over four million people in a large geographical area. Prescription drugs are funded by both public and private programs. Currently, little is known about the trends in pharmacologic treatment for COPD in Alberta. Accordingly, we described the use of pharmacologic therapies for patients newly diagnosed with COPD in the province from fiscal years (FYs) 2010 to 2016 (1 April 2010 to 31 March 2017) in relation to guideline recommendations in place during the timeframe of this study.

\section{Methods}

\section{Data Source And Study Population}

We conducted a retrospective cohort study using six linked administrative health databases in Alberta: National Ambulatory Care Reporting System, Discharge Abstract Database, Practitioner Claims, Pharmaceutical Information Network, Alberta Health Care Insurance Plan (AHCIP) Registry, and Vital Statistics. ${ }^{11}$ The available data elements in Alberta's administrative health databases have been described elsewhere. ${ }^{12,13}$

Patients aged $\geq 35$ years with incident COPD between 1 April 2010 and 31 March 2017 (FYs 2010 to 2016) who were registrants of the AHCIP were included. A patient was considered to have COPD if they had a hospitalization or an outpatient visit with COPD as the primary diagnosis (International Classification of Diseases [ICD], 10th revision, codes J41, J42, J43, and J44). This case definition has a sensitivity of $85 \%$ and a specificity of $78.4 \%$, and has been previously used in research. ${ }^{14,15}$ Incident cases were defined as those who did not have a hospitalization or ambulatory care visit with COPD as either the primary reason or comorbidity in the previous 2 years. Patients were categorized into two groups: 1) incident cases identified at a hospital (hospital patients); and 2) incident cases identified at an outpatient clinic (outpatient patients). The index date indicated when a patient was discharged from the hospital or outpatient clinic with incident COPD. For patients who visited an outpatient clinic with COPD and were admitted to hospital within 1 day, the hospital discharge date was selected as the index date. We further excluded patients who had at least two dispensations of tiotropium, ipratropium, aminophylline, or theophylline within 2 years prior to the index event, as well as patients who died during the index event.

Patients were followed from index date until death, moving out of the province, or being censored by 31 March 2018, representing a minimum follow-up of 12 months for all patients. Study design is presented in Supplemental Figure S1.

\section{Drugs For COPD}

We categorized pharmacologic therapies for patients with COPD into 10 groups, according to recommendations by the Global Initiative for Chronic Obstructive Lung Disease (GOLD): short-acting bronchodilators (SABD) ([1] short-acting $\beta$-agonists [SABA], [2] short-acting muscarinic antagonists [SAMA], and [3] combination SABA/SAMA in one device); long-acting bronchodilators (LABD) ([4] long-acting $\beta$-agonists [LABA], [5] long-acting muscarinic antagonists [LAMA], [6] combination LABA/LAMA in one device, and [7] combination LABA/inhaled corticosteroids [ICS] in one device); [8] ICS; [9] methylxanthines; and [10] phosphodiesterase-4 inhibitors (see Supplemental Table S1). ${ }^{1}$ A variety of COPD medication is available in Canada and was listed in the Alberta Drug Benefit Formulary during the study period (see Supplemental Table S2). ${ }^{16,17}$ As the GOLD guidelines are followed by many Canadian pulmonologists and there was not a significant change in drug recommendations during the study period, we used the 2006 and 2017 versions of these guidelines in this study. ${ }^{1,18,19}$ The latest Canadian Thoracic Society (CTS) position statement on pharmacotherapy for patients with COPD was only made available in December 
2017; therefore, we used the previous CTS recommendations for management of COPD (2007) and the highlights for primary care (2008) as criteria for assessing Canadian guideline adherence. ${ }^{6,20,21}$

\section{Main Outcomes}

The main outcome was the annual rate of utilization of each drug group, which was defined as the proportion of newly diagnosed patients taking a drug group within 30 days of the incident event out of the total newly diagnosed patients in a year. Other outcomes were the distribution of the utilization of each drug group by sex and age (35-59, $60-69,70-79$, and $\geq 80$ years) and by type of incident case (hospital or outpatient setting), drug adherence, and any changes in the proportion of patients taking maintenance therapy over time from the incident event. We also documented the use of antibiotics (Anatomical Therapeutic Chemical [ATC] code J) in addition to COPD medication.

\section{Statistical Analysis}

Patient characteristics were summarized using means ( \pm standard deviation), medians (interquartile ranges), counts, and percentages, as appropriate. The Student T-test or KruskalWallis and $\chi^{2}$ tests were used for continuous and categorical variables, respectively. Patient median household income was based on the 2010 Canada census, and residency (urban or rural) was based on the second digit of the postal code. ${ }^{22,23}$ Previously validated ICD codes were used to identify patient comorbidities and calculate Charlson comorbidity score. ${ }^{24}$ Comorbidities were considered to be present if they were recorded in any secondary field for a hospitalization or ambulatory care visit for incident COPD or in any field for hospitalizations or ambulatory care visits during the 2 years prior to the incident event.

We calculated drug utilization for incident COPD for each drug group. A drug dispensation was considered to be prescription initiated for incident COPD if it was first dispensed within 30 days of the index date. If a second dispensation was within 7 days of the first dispensation, it was considered part of the first dispensation. ${ }^{7}$ A 30-day cut-off was selected based on a practice in Alberta where patients with COPD are usually given a sample of 2 to 4 weeks of drug supply upon discharge. We conducted a sensitivity analysis where we explored drug utilization within 7 days of the index date to examine the effect of the time from incident event to drug utilization. Drug adherence was examined among patients who utilized COPD medication within 30 days of their index date and was defined as the proportion of days with drugs out of the number of eligible days each year after the index date (e. g., number of days from the index date to the end of the year or censored date, whichever came first). If the number of days with drugs was greater than the number of eligible days in that year (e.g., drug dispensation occurred close to the end of that year), then the number of excess days was carried over to the next year. In addition, we calculated drug utilization during each of the 5 years after the incident event regardless of when it was started. Univariate logistic regression was used for trends of drug utilization.

All analyses were performed using Stata version 14 (Stata Corporation, College Station, Texas) and R version 3.5.2 (R Foundation for Statistical Computing, Vienna); two-sided $\mathrm{p}$-values $<0.05$ were considered statistically significant. This study was approved by the Health Research Ethics Board at the University of Alberta (IRB number: Pro00078657).

\section{Results}

There were 55,947 hospitalizations and 135,470 outpatient visits with COPD as the primary diagnosis for 62,079 unique patients aged $\geq 35$ years in Alberta between FYs 2010 and 2016. After excluding 912 patients who did not register with the AHCIP, 15,527 patients who had a hospitalization or outpatient visit with COPD as either the primary reason or a comorbidity during the previous 2 years, 12,051 patients who had two or more dispensations of a COPD-specific drug during the previous 2 years, and 420 patients who died at the incident event, the final study cohort included 33,169 patients with incident COPD. Of them, 24,080 (72.6\%) had their incident event at an outpatient clinic. A flowchart depicting patient selection is presented in Figure 1.

Compared with patients visiting an outpatient clinic, those who were admitted to hospital for COPD were more likely to be female (overall: $50.5 \%$; hospital: $51.5 \%$; outpatient: $50.2 \% ; \mathrm{p}=0.041$ ), older (mean age, overall: 66.1 years; hospital: 72; outpatient: 63.8 ; $\mathrm{p}<0.001)$ and were urban residents (overall: 73\%; hospital: 78.2\%; outpatient: $71 \% ; \mathrm{p}<0.001)$. The proportion of the most elderly group ( $\geq 80$ years) was more than twice as high in the hospital group (33.6\% vs $14.7 \%$; $<0.001$ ). Similarly, patients who were admitted to hospital had higher Charlson comorbidity scores (mean, overall: 1.9; hospital: 2.6; outpatient: 1.7; $\mathrm{p}<0.001)$. Diabetes mellitus $(18.2 \%)$ and heart failure $(10.5 \%)$ were the two most prevalent comorbidities and were both significantly higher in the hospital patients. The 


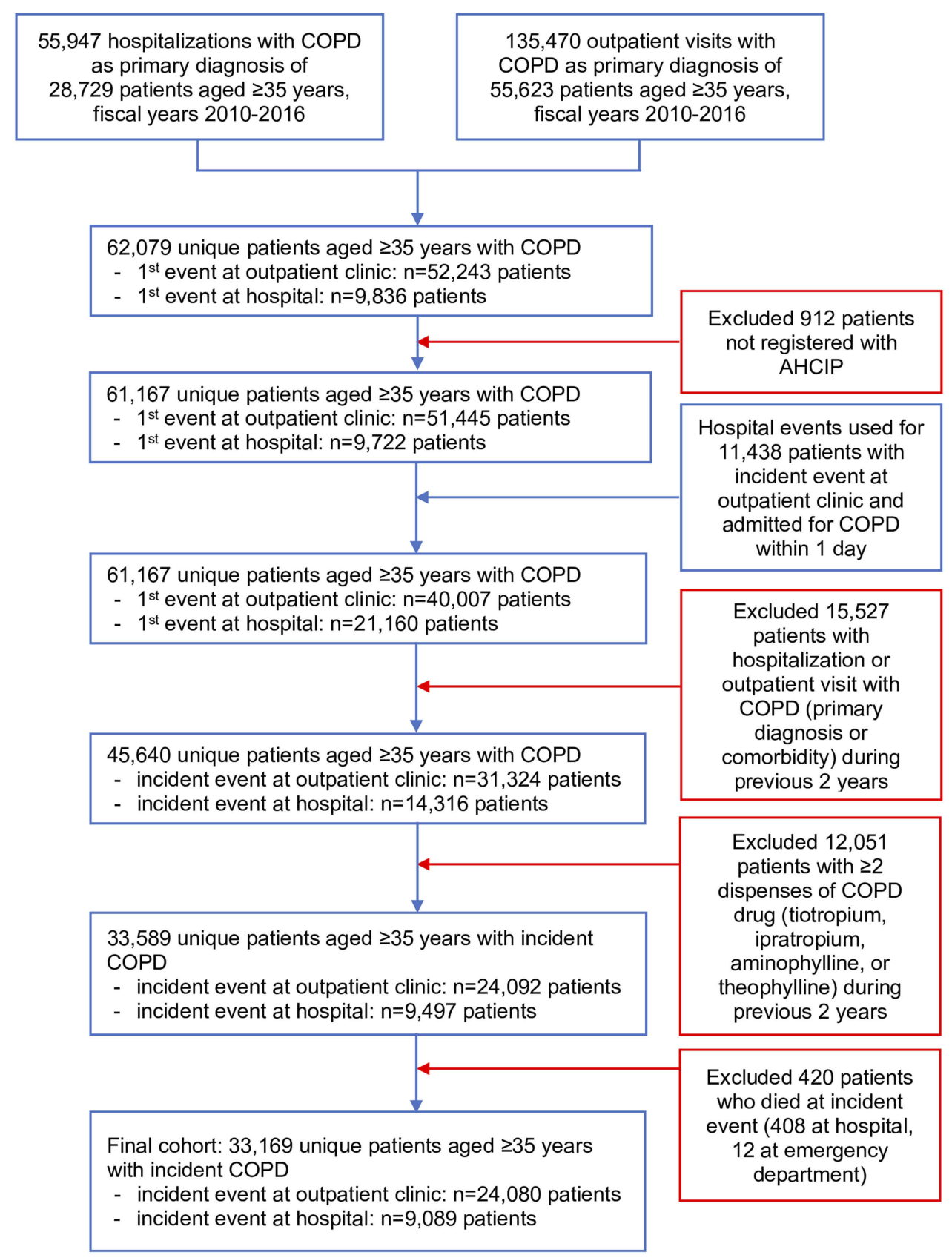

Figure I Patient selection flowchart.

mean follow-up time was 44.1 months and was shorter for the hospital patients (40.2 months) compared with the outpatient patients (45.6 months, $\mathrm{p}<0.001)$ (see Table 1$)$.

\section{Drug Utilization After Incident Event}

Of 33,169 patients with incident COPD, 14.5\% (4,813) did not use any COPD medication during the study period; within 30 days of their index date, $43.7 \%$ did not use any COPD medication. Patients who were admitted to hospital were less likely to omit medication (36.3\%) than their outpatient counterparts $(46.4 \%, \mathrm{p}<0.001)$, as were females (42.3\%) compared with males $(45.1 \%, \mathrm{p}<0.001)$. Over the study period, the proportion of patients who took COPD medication within 30 days of their index date increased (2010: 52.7\%; 2016: 56.6\%; $\mathrm{p}=0.002$ ) as a result of improvement among those admitted to hospital (2010: $56.8 \% ; 2016: 67 \% ; \mathrm{p}<0.001)$.

Of $18,666(56.3 \%)$ patients who took COPD medication within 30 days of their index date, $50.5 \%$ started two or more drugs. Use of SABD (65.5\%) was more common in hospital 
Table I Characteristics Of Studied Population

\begin{tabular}{|c|c|c|c|c|}
\hline Variable & All Patients & Hospital Patients & Outpatient Patients & $\mathbf{p}$ \\
\hline Patients, N & 33,169 & 9,089 & 24,080 & \\
\hline Females, n (\%) & $16,772(50.6)$ & $4,679(51.5)$ & $12,093(50.2)$ & 0.041 \\
\hline Age, in years, mean (SD) & $66.1(13.8)$ & $72(13.1)$ & $63.8(13.4)$ & $<0.001$ \\
\hline Age, in years, median (IQR) & $66(55-77)$ & $73(63-82)$ & $63(54-74)$ & $<0.001$ \\
\hline \multicolumn{5}{|l|}{ Age group, $n(\%)$} \\
\hline $35-59$ years & $11,652(35.1)$ & I,739 (I9.1) & $9,9 \mid 3(4 \mid .2)$ & $<0.001$ \\
\hline $60-69$ years & $8,038(24.2)$ & $2,023(22.3)$ & $6,015(25)$ & \\
\hline 70-79 years & 6,894 (20.8) & $2,27 \mid(25)$ & $4,623(19.2)$ & \\
\hline$\geq 80$ years & 6,585 (19.9) & $3,056(33.6)$ & $3,529(14.7)$ & \\
\hline Urban residence, $\mathrm{n}(\%)$ & $24,203(73)$ & $7,110(78.2)$ & I7,093 (7I) & $<0.001$ \\
\hline \multicolumn{5}{|l|}{ Household income (\$, n, (\%)) } \\
\hline $0-40,000$ & $451(1.4)$ & $145(1.6)$ & $306(1.3)$ & $<0.001$ \\
\hline $40,000-60,000$ & $4,905(14.8)$ & $1,528(16.8)$ & $3,377(14)$ & \\
\hline $60,000-80,000$ & $18,076(54.5)$ & $4,842(53.3)$ & $13,234(55)$ & \\
\hline $80,000-100,000$ & $6,119(18.5)$ & $\mathrm{I}, 587(\mathrm{I} 7.5)$ & $4,532(18.8)$ & \\
\hline$>100,000$ & $3,618(10.9)$ & $987(10.9)$ & $2,631(10.9)$ & \\
\hline \multicolumn{5}{|l|}{ Comorbidities, n (\%) } \\
\hline Myocardial infarction & I,538 (4.6) & $692(7.6)$ & $846(3.5)$ & $<0.001$ \\
\hline Heart failure & $3,474(10.5)$ & I,90I (20.9) & $\mathrm{I}, 573(6.5)$ & $<0.001$ \\
\hline Peripheral vascular disease & $913(2.8)$ & $400(4.4)$ & $513(2.1)$ & $<0.001$ \\
\hline Cerebrovascular disease & $1,162(3.5)$ & $456(5)$ & $706(2.9)$ & $<0.001$ \\
\hline Dementia & $1,084(3.3)$ & $671(7.4)$ & $413(1.7)$ & $<0.001$ \\
\hline Rheumatoid disease & $596(1.8)$ & $223(2.5)$ & $373(1.6)$ & $<0.001$ \\
\hline Peptic ulcer & $488(1.5)$ & $170(1.9)$ & $318(1.3)$ & $<0.001$ \\
\hline Liver disease & 619 (1.9) & $245(2.7)$ & $374(1.6)$ & $<0.001$ \\
\hline Diabetes & $6,039(18.2)$ & $2,33 \mid(25.7)$ & $3,708(15.4)$ & $<0.001$ \\
\hline Hemiplegia or paraplegia & $215(0.7)$ & $100(1.1)$ & $115(0.5)$ & $<0.001$ \\
\hline Renal disease & I,253 (3.8) & $675(7.4)$ & $578(2.4)$ & $<0.001$ \\
\hline Cancer & $1,706(5.1)$ & $743(8.2)$ & $963(4)$ & $<0.001$ \\
\hline Metastatic cancer & $510(1.5)$ & $217(2.4)$ & $293(1.1)$ & $<0.001$ \\
\hline Charlson comorbidity score, mean (SD) & $1.9(1.7)$ & $2.6(2)$ & $1.7(1.5)$ & $<0.001$ \\
\hline Follow-up time, month, median (SD) & $44.1(25.7)$ & $40.2(25.8)$ & $45.6(25.4)$ & $<0.001$ \\
\hline
\end{tabular}

Abbreviations: IQR, interquartile range; SD, standard deviation.

patients $(68.6 \%)$ compared with their outpatient counterparts $(64.1 \% ; \mathrm{p}<0.001)$, as was use of LABD (average 59.2\%; $73.9 \%$ in hospital patients vs $52.7 \%$ in outpatient patients; $\mathrm{p}<0.001)$. SABA $(60.5 \%)$ and LABA/ICS (41.6\%) were the two most common drugs. While the proportion of patients taking SABA remained unchanged (2010: 60.4\%; 2016: 61.7; $\mathrm{p}=0.570$ ), the proportion of patients taking LABA/ICS decreased over time (2010: 42.5\%; 2016: 35.9\%; $<<0.001$ ). ICS (without LABA) was used in $14.2 \%$ of patients and as monotherapy in $4.5 \%$ of patients. The proportion of patients who took any ICS was similar in both settings (hospital: $56.7 \%$; outpatient: $55.7 \%$; $=0.194$ ) and decreased in both settings over time $(\mathrm{p}<0.001)$. However, hospital patients used more LABA/ICS (48.6\% vs $38.5 \%, \mathrm{p}<0.001)$ and less ICS in a single device $(10 \%$ vs $19 \%, \mathrm{p}<0.001)$ compared with their outpatient counterparts (see Figure 2 and Table 2).

LAMA was more commonly used in hospital patients $(52.5 \%)$ than in their outpatient counterparts $(20.8 \%$; $\mathrm{p}<0.001)$. Combination LABA/LAMA in a single device was first used in $2014(0.3 \%)$ and increased 10-fold in just 3 years (see Table 2). However, $15.3 \%$ of patients were started with both LAMA and LABA, and use of this combination was higher in hospital patients $(29.5 \%)$ than in outpatient patients $(9 \%, \mathrm{p}<0.001)$.

The proportion of patients who started SABD was similar between females $(65.4 \%)$ and males $(65.6 \%, p=0.742)$, while 


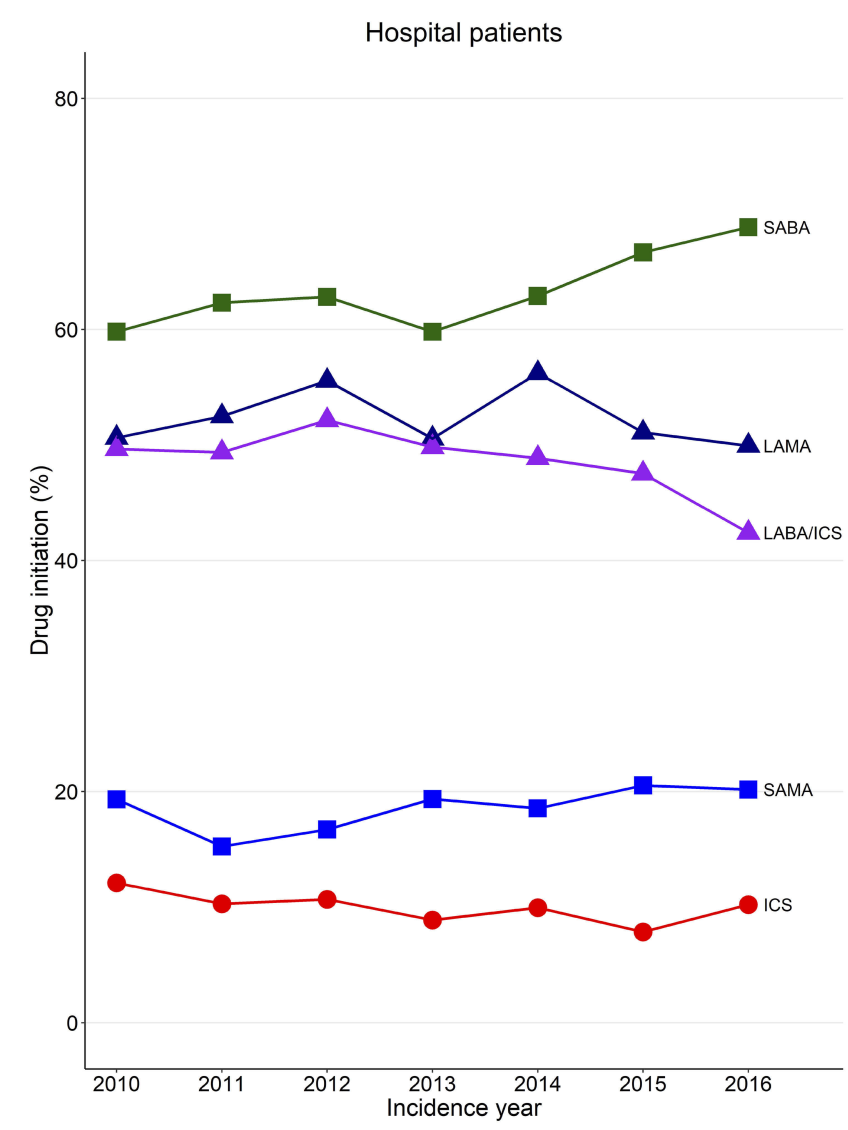

Figure 2 Initiation of key drug group for COPD patients.

the proportion of patients who started LABD was lower among females $(58.2 \%$ vs $60.4 \%, \mathrm{p}=0.002)$. The most senior patients (aged $\geq 80$ years) were less likely to start SABD $(63.8 \%$ vs $65.9 \%, \mathrm{p}=0.022)$ or any ICS $(54.1 \%$ vs $56.5 \%$, $\mathrm{p}=0.010)$ but more likely to start LABD $(64.4 \%$ vs $58 \%$, $\mathrm{p}<0.001$ ) than their younger counterparts (see Supplemental Table S3).

Antibiotics were started in $56 \%$ of patients and were more frequently used in outpatient (57\%) compared with hospital patients $(53.1 \%, \mathrm{p}<0.001)$. Antibiotics were used in $66.5 \%, 60.2 \%$, and $63.6 \%$ of patients who started SABD, LABD, and any ICS, respectively.

Restricting the time to drug initiation to 7 days led to $55.4 \%$ of patients without any COPD medication after their incident event. Of those who started drugs, SABA (63.1\%) and LABA/ICS (40.9\%) remained the most common drugs (see Supplemental Table S4).

\section{Drug Adherence Among Initiators}

Among 18,666 patients who took drugs within 30 days of their incident event, drug adherence was 54.3\% and was higher among hospital patients (66.5\%) compared with

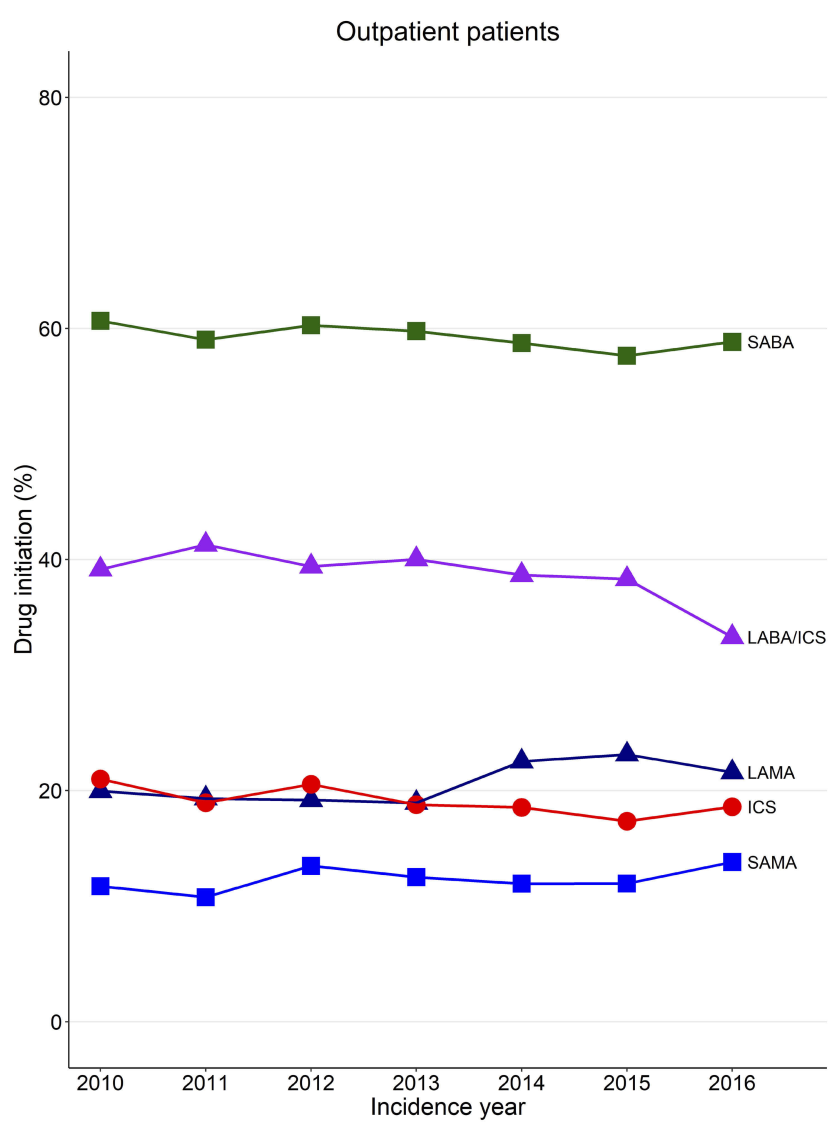

outpatient patients $(48.9 \%, \mathrm{p}<0.001)$ during the first year after the incident event. Drug adherence increased to $73.9 \%$ and $60.3 \%$ in hospital and outpatient patients, respectively, during the second year, and remained relatively stable during the next 3 years (see Figure 3). Over the study period, drug adherence during the first year after the incident event improved (2010: 53.4\%; 2016: 57.4\%; $\mathrm{p}<0.001$ ) due to better adherence in outpatient patients (2010: 47.6\%; 2016: 53\%; $<<0.001)$ but remained unchanged in hospital patients (2010: 66\%; 2016: 68.3\%; $\mathrm{p}=0.174)$.

\section{Drug Utilization Over Time From Incident Event}

The proportion of patients who did not use any COPD maintenance medication increased from $23.6 \%$ in the first year to $40.3 \%(\mathrm{p}<0.001)$ in the second year after the incident event and remained relatively unchanged thereafter. Accordingly, the proportion of patients who used SABA and SAMA decreased from $73.5 \%$ and $17.9 \%$ in the first year to $66 \%$ and $12.3 \%$ in the second year (both $\mathrm{p}<0.001$ ), respectively (see Table 3 ). In contrast, the 


\begin{tabular}{|c|c|c|c|c|c|c|c|c|c|c|}
\hline & 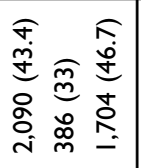 & 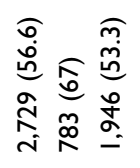 & 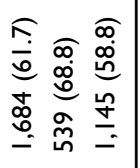 & 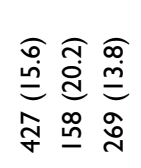 & 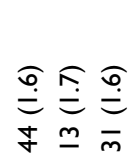 & 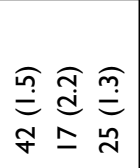 & 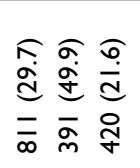 & 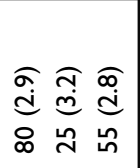 & 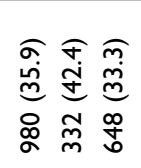 & 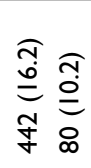 \\
\hline & 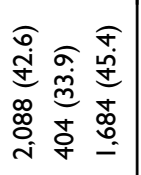 & 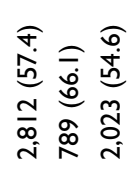 & 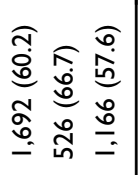 & 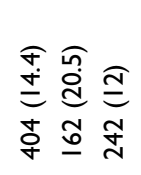 & 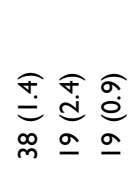 & 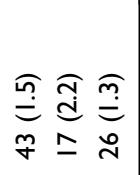 & 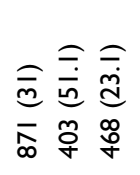 & 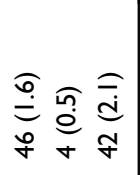 & 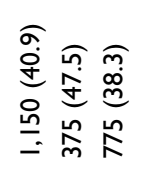 & 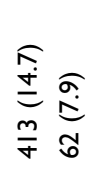 \\
\hline & 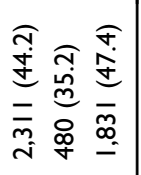 & 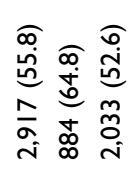 & 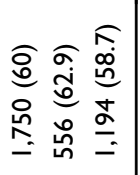 & 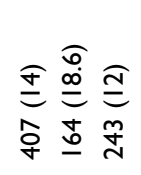 & 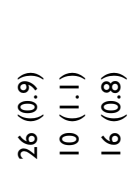 & 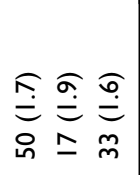 & 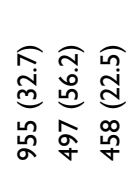 & 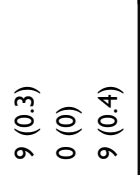 & 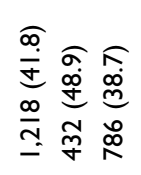 & 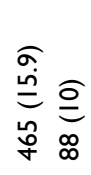 \\
\hline & 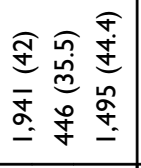 & 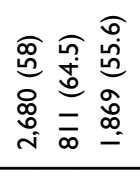 & 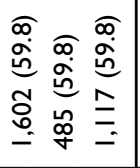 & 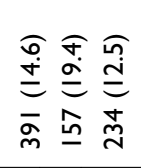 & 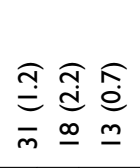 & 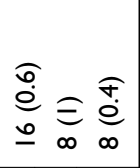 & 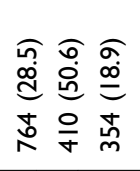 & $\begin{array}{ccc}\widehat{a} & \widehat{a} \\
0 & 0 & 0\end{array}$ & 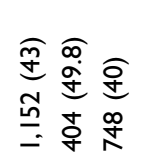 & 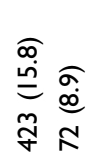 \\
\hline & 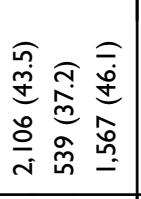 & 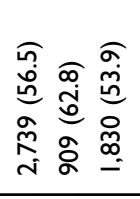 & 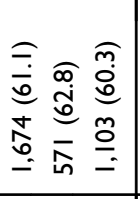 & 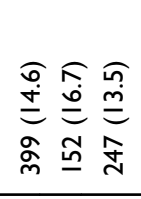 & 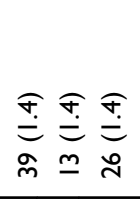 & 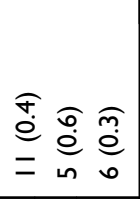 & 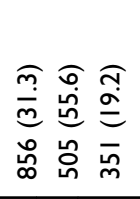 & 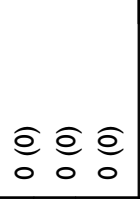 & 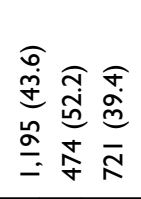 & 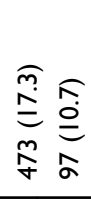 \\
\hline & 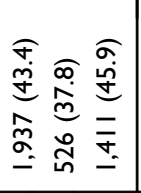 & 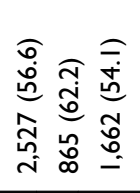 & 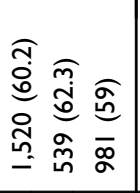 & 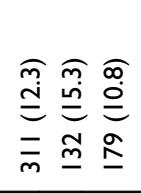 & 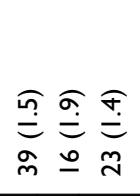 & 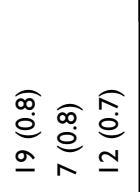 & 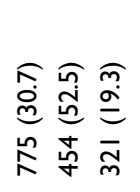 & $\begin{array}{l}\widehat{a} \widehat{o} \\
0 \\
0\end{array}$ & 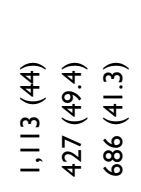 & 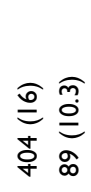 \\
\hline & 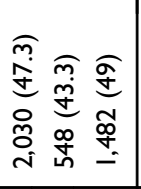 & 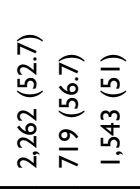 & 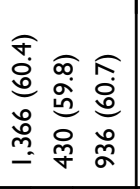 & 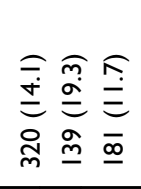 & 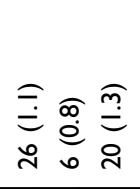 & 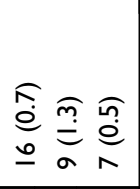 & 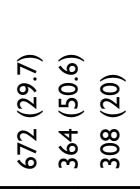 & $\begin{array}{l}\widehat{\hat{a}} \widehat{\hat{a}} \\
0\end{array}$ & 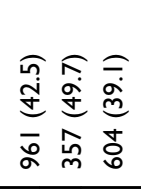 & 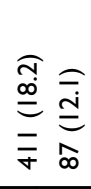 \\
\hline & 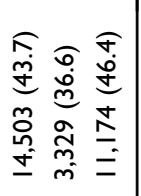 & 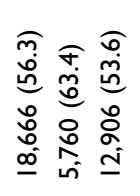 & 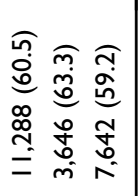 & 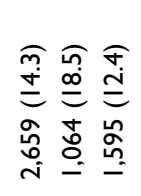 & 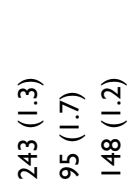 & 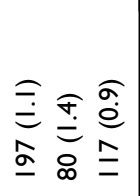 & 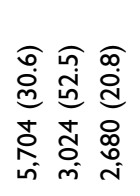 & 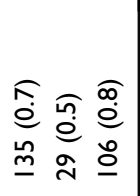 & 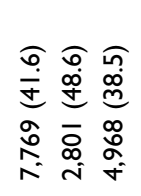 & 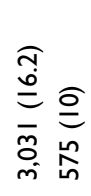 \\
\hline & 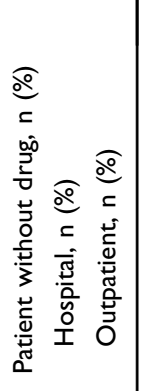 & 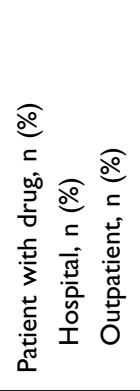 & 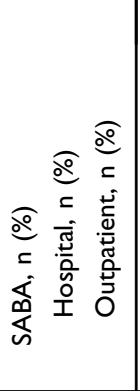 & 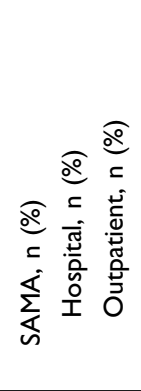 & 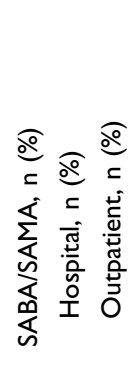 & 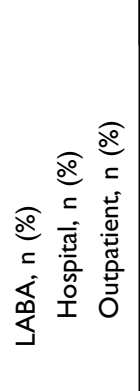 & 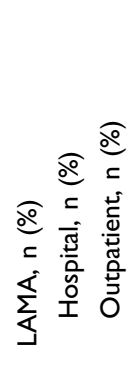 & 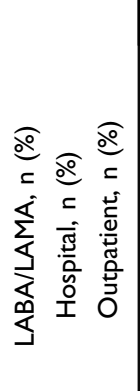 & 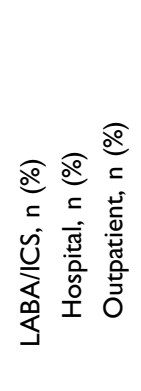 & 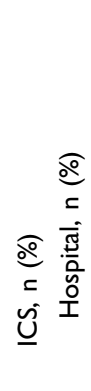 \\
\hline
\end{tabular}




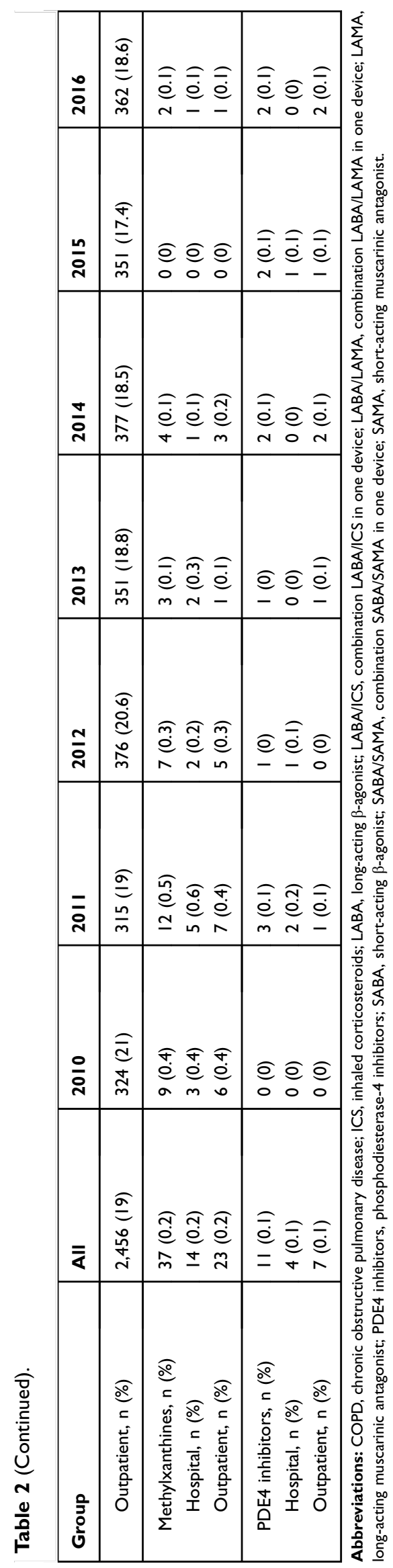

proportion of patients using LAMA increased from $40.3 \%$ to $45.7 \%(p<0.001)$ during the 5 years after the incident event, while the proportion of patients using LABA/ICS and ICS remained relatively stable over time. Among patients who used COPD medication, the proportion of patients who used three or more drug classes in a year remained unchanged during follow-up (first year: 38.9\%; fifth year: $38.6 \% ; \mathrm{p}=0.688$ ).

\section{Discussion}

Our population-based study of 33,169 patients with incident COPD between 2010 and 2016 shows that a significant portion of patients did not start medication after diagnosis. Overall, $14.5 \%$ of patients did not use any COPD medication during the study period, and $43.7 \%$ did not start medication within 30 days of the first diagnosis. However, the proportion of patients taking medication increased over time. SABA and LABA/ICS were the two most commonly used drugs. While use of SABA after the incident event remained stable over time, the use of LABA/ICS and any ICS decreased over time. While hospital patients were prescribed more LABA/ICS in combination, outpatient patients were initiated more ICS in a single device. Approximately one-fifth of patients were given ICS without LABA or as a monotherapy. The proportion of patients taking maintenance medication dropped significantly from $76.4 \%$ in the first year to $59.7 \%$ in the second year after incident event and remained relatively stable during the following years. Drug adherence was low during the first year after the incident event (54.3\%) but improved over time. Hospital patients had better adherence than outpatient patients.

Our finding of poor drug utilization is consistent with previously reported results. Ingebrigtsen et al reported that only $42.2 \%$ of patients with COPD in Denmark were treated with medication during the first year after spirometry results (FEV ${ }_{1}<60 \%$ predicted). ${ }^{25}$ Similarly, in a retrospective study in Manitoba, Canada, Falk et al reported that 31\% of patients did not use any medication after COPD diagnosis, which is double the amount of our finding. ${ }^{7}$ However, Falk et al did not report drug initiation according to time from the first diagnosis, and there was a substantial latency in drug initiation after the first diagnosis, evident by significantly higher non-initiators when the time from the index date to drug initiation was taken into consideration. Our contemporary cohort of patients with incident COPD, as well as the various efforts to improve patient medication uptake and adherence (e.g., self-management, brief counselling, community-based education and support program using case managers, and innovative technology such as 


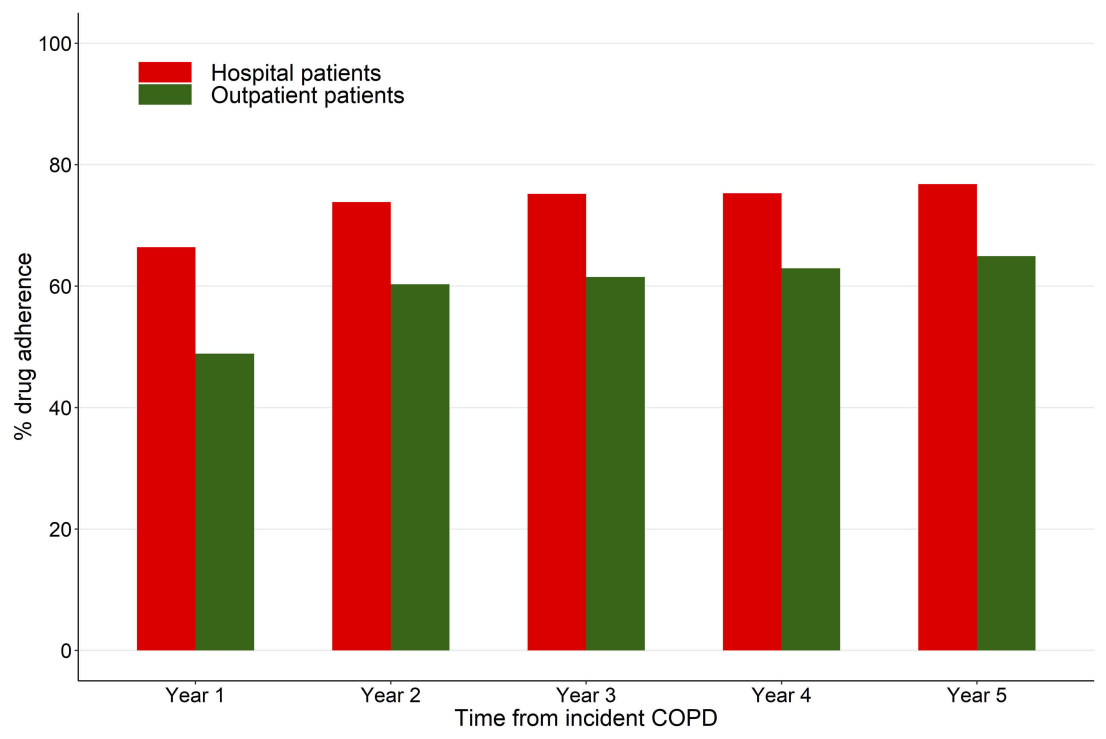

Figure 3 Drug adherence for COPD patients.

wearable devices) could all be reasons for the improved drug initiation over time that we observed. ${ }^{26-29}$ We also could not exclude the effect of the introduction of more effective drugs (i.e., LAMAs are superior to SABD) and dual bronchodilation is superior to monotherapy during the study period. Nevertheless, the proportion of patients who did not use any COPD medication in the present study is still substantial enough to prompt additional research to inform factors associated with non-initiation and help design a patient education program.
The GOLD and CTS guidelines recommend initiation of SABD at early diagnosis as needed and then initiation of LABD and ICS as the severity increases, with ICS started only at a severe stage (i.e., stage III with frequent exacerbations or one or more hospital admission with COPD). However, a significant proportion of patients newly diagnosed with COPD at an outpatient clinic started ICS immediately after diagnosis, suggesting that ICS may be initiated earlier than needed. In addition, our finding that approximately $19 \%$ of patients started ICS as monotherapy or without LABA

Table 3 COPD Drug Utilization Over Time After Incident Event In Alberta, 2010-2016

\begin{tabular}{|c|c|c|c|c|c|}
\hline \multirow[t]{2}{*}{ Group } & \multicolumn{5}{|c|}{ Time From Incident Event } \\
\hline & Year I & Year 2 & Year 3 & Year 4 & Year 5 \\
\hline Patient, $\mathrm{N}$ & 33,169 & 30,314 & 24,444 & $|9,07|$ & 13,953 \\
\hline Patient without drug, n (\%) & $7,838(23.6)$ & $|2,2| 7(40.3)$ & $10,106(41.3)$ & $7,902(4 I .4)$ & $5,878(42.1)$ \\
\hline Patient with drug, n (\%) & $25,331(76.4)$ & $18,097(59.7)$ & $14,338(58.7)$ & $11,169(58.6)$ & $8,075(57.9)$ \\
\hline SABA, n (\%) & $18,607(73.5)$ & $11,952(66)$ & $9,625(67.1)$ & $7,486(67)$ & $5,542(68.6)$ \\
\hline SAMA, n (\%) & $4,535(17.9)$ & $2,23 \mid(12.3)$ & $1,752(12.2)$ & $1,383(12.4)$ & $\mathrm{I}, 083(13.4)$ \\
\hline SABA/SAMA, n (\%) & $526(2.1)$ & $325(1.8)$ & $287(2)$ & $223(2)$ & $196(2.4)$ \\
\hline LABA, n (\%) & $557(2.2)$ & $404(2.2)$ & $302(2.1)$ & $248(2.2)$ & $184(2.3)$ \\
\hline LAMA, n (\%) & $10,207(40.3)$ & $7,387(40.8)$ & $6,100(42.5)$ & $4,895(43.8)$ & $3,690(45.7)$ \\
\hline LABA/LAMA, n (\%) & $526(2.1)$ & $579(3.2)$ & $492(3.4)$ & $406(3.6)$ & $353(4.4)$ \\
\hline LABA/ICS, n (\%) & $14,997(59.2)$ & $10,576(58.4)$ & $8,549(59.6)$ & $6,611(59.2)$ & $4,810(59.6)$ \\
\hline ICS, n (\%) & $7,324(28.9)$ & $5,069(28)$ & $3,887(27.1)$ & $3,085(27.6)$ & $2,180(27)$ \\
\hline Methylxanthines, n (\%) & $98(0.4)$ & $80(0.4)$ & $78(0.5)$ & $56(0.5)$ & $45(0.6)$ \\
\hline PDE4 inhibitors, n (\%) & $72(0.3)$ & $83(0.5)$ & $55(0.4)$ & $56(0.5)$ & $44(0.5)$ \\
\hline
\end{tabular}

Abbreviations: COPD, chronic obstructive pulmonary disease; ICS, inhaled corticosteroids; LABA, long-acting $\beta$-agonist; LABA/ICS, combination LABA/ICS in one device; LABA/LAMA, combination LABA/LAMA in one device; LAMA, long-acting muscarinic antagonist; PDE4 inhibitors, phosphodiesterase-4 inhibitors; SABA, short-acting $\beta$ agonist; SABA/SAMA, combination SABA/SAMA in one device; SAMA, short-acting muscarinic antagonist. 
indicates poor guideline adherence for ICS initiation, as previously reported in other jurisdictions. ${ }^{7,9,18,20}$ This practice may potentially result in more harm than good to patients. While the use of ICS reduces airway inflammation and exacerbation when administered with LABD, it is also associated with an increased risk of pneumonia and other complications. $^{30-32}$

Similar to Falk et al, we found that SABA was the most commonly used drug after the first diagnosis, and the proportion of patients who initiated SABD is relatively comparable between the two studies. However, we observed a much higher proportion of patients who initiated LABA/ICS, LAMA or a combination of LABA and LAMA. This trend, in combination with higher proportion of patients with LAMA or combination of LABA/LAMA in the hospital group, may reflect both availability of drugs and guideline-based treatments for more severe patients with LABD (e.g., hospital patients), especially in the context of favourable outcomes for the LABA/LAMA combination, to prevent moderate-tosevere exacerbations and improve quality of life. ${ }^{20,33}$

We found that the change in the proportion of patients taking medication occurs mainly between the first and the second year after COPD diagnosis, and patients with their incident event at an outpatient clinic were more vulnerable to non-uptake and non-adherence. This may be because of higher severity of COPD in hospital patients compared with their outpatient counterparts. It has been reported previously that the use of and adherence to maintenance medication are positively associated with the severity of COPD, and acute exacerbation is a strong predictor of medication treatment uptake. $^{10,25}$ The changes in the proportion of patients taking medication and drug adherence between the first and the second year suggest that early medication uptake and adherence education interventions after the incident event might make a bigger impact, especially due to the importance of correct inhaler technique and high prevalence of critical inhaler errors among patients. ${ }^{34}$ As seen in a recent systematic review by Bryant et al, studies of several interventions have included only patients who were confirmed with COPD for more than a year or who were on theophylline for a month or more. $^{26}$ Therefore, additional research is needed to draw a conclusion.

We found that more than half of the outpatient patients started antibiotics and there were more antibiotics users in outpatient than in hospital patients. The GOLD and CTS guidelines recommend antibiotics for purulent acute exacerbation (i.e., increased sputum, sputum purulence, and increased dyspnea) only. ${ }^{1,20,21}$ Therefore, higher use of antibiotics in outpatient setting may be an indication of overuse of antibiotics which was already documented in other jurisdictions. For example, a study in Spain reported frequent antibiotics use $(84.5 \%)$ for patients with COPD in primary care setting. ${ }^{35}$ Another study in six European countries also found frequent antibiotics use in primary care for patients with COPD (ranged from $49 \%$ in Denmark to $93 \%$ in Russia). ${ }^{36}$ Even though the clinical benefit of antibiotics has been reported not only in COPD patients with severe exacerbation but also in patients with mild-to-moderate exacerbations, ${ }^{37-39}$ overuse of antibiotics could be associated with an increased risk of co-infections such as Clostridioides difficile colitis or increased drug resistance. ${ }^{40,41}$

Our study provides novel data on the temporal trends of maintenance medication for incident COPD, using a contemporary dataset of patients with incident COPD from heterogenous health facilities of an integrated health care system in a large and diverse geographic region with a population of over 4 million people. The findings are likely to be generalizable to other jurisdictions with similar health care system structures. However, our findings were based on drug dispensation claims, so we could not evaluate prescriptions that were not filled due to primary non-adherence. Nevertheless, we believe that the low proportion of patients not using any COPD medication (15\%) should not significantly affect the overall findings. Further, we did not have information on the quality of inhaler device, nor on actual use by patients. However, while other studies used prescribing data, the claims data used in this study provide information on actual dispensation of therapy, which is a strength as these data are closer to real consumption than prescribing data. In addition, the selection of a benchmark time of 30 days after the index event is arbitrary and it may lead to a short period of time to have prescription dispensed for patients who had a full 4-week drug sample. However, adding additional 15 days to the benchmark time led to only an additional $3.7 \%$ of patients initiating drug. Therefore, it should not affect the overall findings.

\section{Conclusion}

Our population-based study of patients with COPD shows that the initiation of and adherence to maintenance therapy after the incident event is low, but is slightly improving over time. Hospital patients have better medication initiation and adherence than outpatient patients. SABA and LABA/ICS are the two most commonly initiated drugs, and ICS utilization decreases over time. In order to increase the uptake of the evidence-based therapy and improve COPD management, 
further education for prescribers and effective and ongoing patient education are needed.

\section{Funding}

This research has been commissioned and funded by the Ontario Lung Association, as part of Helping the Missing Million project.

\section{Disclosure}

The Lung Association - Ontario funded the research for this study with an unrestricted grant to the Institute of Health Economics (IHE). Dat T Tran and Ilke Akpinar are IHE employees. Dr Dat $\mathrm{T}$ Tran reports grants from Lung Association- Ontario, during the conduct of the study. Dr Ilke Akpinar reports grants from Lung Association - Ontario, during the conduct of the study. Dr Philip Jacobs reports grants from Lung Association Ontario, during the conduct of the study; and grant from Boehringer Ingelheim to study COPD market. The authors report no other conflicts of interest to this work.

\section{References}

1. Vogelmeier CF, Criner GJ, Martinez FJ, et al. Global strategy for the diagnosis, management, and prevention of chronic obstructive lung disease 2017 report. GOLD executive summary. Am J Respir Crit Care Med. 2017;195:557-582. doi:10.1164/rccm.201701-0218PP

2. Naghavi M, Abajobir AA, Abbafati C, et al. Global, regional, and national age-sex specific mortality for 264 causes of death, 1980-2016: a systematic analysis for the Global Burden of Disease Study 2016. Lancet. 2017;390:1151-1210. doi:10.1016/S0140-6736(17)32152-9

3. Evans J, Chen Y, Camp PG, Bowie DM, McRae L. Estimating the prevalence of COPD in Canada: reported diagnosis versus measured airflow obstruction. Health Rep. 2014;25:3-11.

4. Statistics Canada. Chronic obstructive pulmonary disease under-diagnosed in Canadian adults: results from cycles 3 and 4 (2012 to 2015) of the Canadian Health Measures Survey. Available from: http://www.stat can.gc.ca/pub/82-625-x/2017001/article/14701-eng.htm. Accessed December 13, 2017.

5. Statistics Canada. Table: 17-10-0057-01 (formerly CANSIM 052-0005) projected population, by projection scenario, age and sex, as of July 1 ( $\mathrm{x}$ 1,000). Available from: http://www5.statcan.gc.ca/cansim/pick-choisir? lang=eng\&p2=33\&id=0520005. Accessed February 7, 2018.

6. Bourbeau J, Bhutani M, Hernandez P, et al. CTS position statement: pharmacotherapy in patients with COPD - an update. Can J Respir Crit Care Sleep Med. 2017;1:222-241. doi:10.1080/24745332.2017.1395588

7. Falk J, Dik N, Bugden S. An evaluation of early medication use for COPD: a population-based cohort study. Int J Chron Obstruct Pulmon Dis. 2016;11:3101-3108. doi:10.2147/COPD.S123643

8. Ford ES, Mannino DM, Giles WH, Wheaton AG, Liu Y, Croft JB. Prescription practices for chronic obstructive pulmonary disease: findings from the national ambulatory medical care survey 1999-2010. COPD. 2014;11:247-255. doi:10.3109/15412555.2013.840570

9. Bourbeau J, Sebaldt RJ, Day A, et al. Practice patterns in the management of chronic obstructive pulmonary disease in primary practice: the CAGE study. Can Respir J. 2008;15:13-19. doi:10.1155/2008/173904
10. Ingebrigtsen TS, Marott JL, Nordestgaard BG, et al. Low use and adherence to maintenance medication in chronic obstructive pulmonary disease in the general population. J Gen Intern Med. 2015;30:5159. doi:10.1007/s11606-014-3029-0

11. Alberta Health. Overview of administrative health datasets. Available from: https://open.alberta.ca/dataset/657ed26d-eb2c-4432-b9cb0ca2158f165d/resource/38f47433-b33d-4d1e-b959-df312e9d9855/ download/Research-Health-Datasets.pdf. Accessed December 1, 2017.

12. Tran DT, Ohinmaa A, Thanh NX, Welsh RC, Kaul P. The healthcare cost burden of acute myocardial infarction in Alberta, Canada. Pharmacoecon Open. 2017;2:433-442. doi:10.1007/s41669-017-0061-0

13. Islam S, Kaul P, Tran DT, Mackie AS. Health care resource utilization among children with congenital heart disease: a population-based study. Can J Cardiol. 2018;34:1289-1297. doi:10.1016/j.cjca.2018.06.011

14. Gershon AS, Wang C, Guan J, Vasilevska-Ristovska J, Cicutto L, To T. Identifying individuals with physcian diagnosed COPD in health administrative databases. COPD. 2009;6:388-394. doi:10.1080/1541255090 3140865

15. Tran DT, Thanh NX, Ohinmaa A, Mayers I, Jacobs P. Current and future direct healthcare cost burden of chronic obstructive pulmonary disease in Alberta, Canada. Can J Respir Crit Care Sleep Med. 2019;1-9.

16. Health Canada. Drug Product Database Online Query. Ottawa, Ontario, Canada: Health Canada; 2017.

17. Alberta Health. Interactive drug benefit list. Available from: https:// www.ab.bluecross.ca/dbl/publications.html. Accessed May 10, 2018.

18. Fromer L, Cooper CB. A review of the GOLD guidelines for the diagnosis and treatment of patients with COPD. Int $J$ Clin Pract. 2008;62:1219-1236. doi:10.1111/j.1742-1241.2008.01807.x

19. Global Initiative for Chronic Obstructive Lung Disease. Global Strategy For The Diagnosis, Management, And Prevention OfChronic Obstructive Pulmonary Disease. Vol. 2006. Geneva, Switzerland: World Health Organization; 2006.

20. O'Donnell DE, Aaron S, Bourbeau J, et al. Canadian Thoracic Society recommendations for management of chronic obstructive pulmonary disease - 2007 update. Can Respir J. 2007;14 Suppl B:5b-32b. doi:10.1155/ $2007 / 830570$

21. O'Donnell DE, Hernandez P, Kaplan A, et al. Canadian Thoracic Society recommendations for management of chronic obstructive pulmonary disease -2008 update - highlights for primary care. Can Respir J. 2008;15 Suppl A:1a-8a.

22. University of Alberta Libraries. Data library. 2010 Census of Canada. 2012.

23. Statistics Canada. Postal code conversion file (PCCF), reference guide. Available from: https://www150.statcan.gc.ca/n1/pub/92-153g/2011002/tech-eng.htm. Accessed February 2, 2019

24. Quan H, Sundararajan V, Halfon P, et al. Coding algorithms for defining comorbidities in ICD-9-CM and ICD-10 administrative data. Med Care. 2005;43:1130-1139. doi:10.1097/01.mlr.0000182534.19832.83

25. Ingebrigtsen TS, Marott JL, Vestbo J, et al. Characteristics of undertreatment in COPD in the general population. Chest. 2013;144:18111818. doi:10.1378/chest.13-0453

26. Bryant J, McDonald VM, Boyes A, Sanson-Fisher R, Paul C, Melville J. Improving medication adherence in chronic obstructive pulmonary disease: a systematic review. Respir Res. 2013;14:109. doi:10.1186/1465-9921-14-19

27. Wu R, Liaqat D, de Lara E, et al. Feasibility of using a smartwatch to intensively monitor patients with chronic obstructive pulmonary disease: prospective cohort study. JMIR mHealth uHealth. 2018;6: e10046. doi:10.2196/10046

28. Bourbeau J, Julien M, Maltais F, et al. Reduction of hospital utilization in patients with chronic obstructive pulmonary disease: a disease-specific self-management intervention. Arch Intern Med. 2003;163:585-591. doi:10.1001/archinte.163.5.585 
29. Lenferink A, van der Palen J, Effing T. The role of social support in improving chronic obstructive pulmonary disease self-management. Expert Rev Respir Med. 2018;1-4.

30. Lipson DA, Barnhart F, Brealey N, et al. Once-daily single-inhaler triple versus dual therapy in patients with COPD. $N$ Engl J Med. 2018;378:1671-1680. doi:10.1056/NEJMoa1713901

31. Papi A, Vestbo J, Fabbri L, et al. Extrafine inhaled triple therapy versus dual bronchodilator therapy in chronic obstructive pulmonary disease (TRIBUTE): a double-blind, parallel group, randomised controlled trial. Lancet. 2018;391:1076-1084. doi:10.1016/S0140-6736(18)30206-X

32. Singh S, Loke YK. Risk of pneumonia associated with long-term use of inhaled corticosteroids in chronic obstructive pulmonary disease: a critical review and update. Curr Opin Pulm Med. 2010;16:118-122. doi:10.1097/MCP.0b013e328334c085

33. Tariq SM, Thomas EC. Maintenance therapy in COPD: time to phase out ICS and switch to the new LAMA/LABA inhalers? Int J Chron Obstruct Pulmon Dis. 2017;12:1877-1882. doi:10.2147/COPD.S138006

34. Al-Showair RA, Tarsin WY, Assi KH, Pearson SB, Chrystyn H. Can all patients with COPD use the correct inhalation flow with all inhalers and does training help? Respir Med. 2007;101:2395-2401. doi:10.1016/j.rmed.2007.06.008

35. Murio C, Soler X, Perez M, Calero G, Ruiz-Manzano J. Acute exacerbation of chronic obstructive pulmonary disease in primary care setting in Spain: the EPOCAP study. Ther Adv Respir Dis. 2010;4:215-223. doi:10.1177/1753465810374611
36. Llor C, Bjerrum L, Munck A, et al. Predictors for antibiotic prescribing in patients with exacerbations of COPD in general practice. Ther Adv Respir Dis. 2013;7:131-137. doi:10.1177/175346581247 2387

37. Llor C, Moragas A, Hernandez S, Bayona C, Miravitlles M. Efficacy of antibiotic therapy for acute exacerbations of mild to moderate chronic obstructive pulmonary disease. Am J Respir Crit Care Med. 2012;186:716-723. doi:10.1164/rccm.2012060996OC

38. Butorac-Petanjek B, Parnham MJ, Popovic-Grle S. Antibiotic therapy for exacerbations of chronic obstructive pulmonary disease (COPD). J Chemother. 2010;22:291-297. doi:10.1179/ joc.2010.22.5.291

39. Huckle AW, Fairclough LC, Todd I. Prophylactic antibiotic use in COPD and the potential anti-inflammatory activities of antibiotics. Respir Care. 2018;63:609-619. doi:10.4187/respcare.05943

40. Brett AS, Al-Hasan MN. COPD exacerbations - a target for antibiotic stewardship. $N$ Engl J Med. 2019;381:174-175. doi:10.1056/ NEJMe1905520

41. Serisier DJ. Risks of population antimicrobial resistance associated with chronic macrolide use for inflammatory airway diseases. Lancet Respir Med. 2013;1:262-274. doi:10.1016/S2213-2600(13) 70038-9

\section{Publish your work in this journal}

The International Journal of COPD is an international, peer-reviewed journal of therapeutics and pharmacology focusing on concise rapid reporting of clinical studies and reviews in COPD. Special focus is given to the pathophysiological processes underlying the disease, intervention programs, patient focused education, and self management protocols. This journal is indexed on PubMed Central, MedLine and CAS. The manuscript management system is completely online and includes a very quick and fair peer-review system, which is all easy to use. Visit http://www.dovepress.com/testimonials.php to read real quotes from published authors. 